\title{
Gilka Machado e Florbela Espanca: uma poética do donjuanismo feminino
}

Cleonice Nascimento da Silva UNESP - Assis

\section{Entre o sagrado e o profano...}

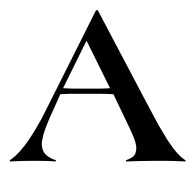

história sagrada e a história profana encontravam-se paralelas já no período medieval. Entretanto, esse paralelismo não incorria numa transposição de uma situação social para um mito. "Os mitos conhecidos pela Idade Média, quaisquer que fossem suas procedências, eram entendidos e vivenciados de forma própria àquele momento". ${ }^{1}$

A informação isolada de que as mitologias existentes na Europa Medieval teriam sido absorvidas pelo clero como forma de combater o paganismo esconde o essencial, que eram as motivações econômicas e de evangelização. A possibilidade de transformar os cultos pagãos em oferendas cristãs revela, acima de tudo, uma mesma estrutura em comum. Apesar das bases cristãs inverterem o sentido do sacrifício, que não era mais do homem pelo Deus, e sim do Deus pelo homem, prevalecia o sentido do sacrifício que agora era de um homem (o Filho encarnado), para que interferisse diante de Deus (o Pai). Durante muito tempo os cristãos cultivaram o sacrifício como forma de obter as graças desejadas, sendo este um forte resquício dos comportamentos míticos existentes no próprio clero.

A relação entre cristianismo e mito, negada na época, se completa e faz parte de um processo que visa à compreensão do sentido profundo de ambos. O cristianismo medieval tem que ser visto, antes de mais nada como

${ }^{1}$ HILÁRIO JÚNIOR, 1996. p. 49. 
um vasto sistema de representações mentais, verbais, gestuais e imagísticas; uma visão de mundo construída historicamente com elementos de variadas procedências, (...) e acima de tudo, (...) o cristianismo medieval era um conjunto de crenças e valores que articulava todas as instâncias do universo, ${ }^{2}$

trazendo uma certa segurança ao espírito que se abalava diante das forças da natureza e dos mistérios do mundo.

A existência de um paralelismo entre figuras míticas e figuras bíblicas pode ser constatado na figura da Virgem Maria: o casamento sagrado de Maria com o Espírito Santo "pouco se diferenciava das tradicionais hierogamias, pois a Virgem era indiscutivelmente uma nova hipóstase das antiqüíssimas Mães-Terra”. ${ }^{3}$

Até mesmo o caráter canibalesco dos sacrifícios pode ser encontrado no cristianismo pois,

o sacrificado deve ser devorado pelos seus seguidores: 'Tomai e comei, isto é o meu corpo', o fato de a hóstia cristã tornar-se a carne de Deus através de um rito, não o descaracteriza enquanto canibalismo. ${ }^{4}$

Para o autor, a Bíblia é o grande repertório mitológico do cristianismo, pois $a$ Bíblia cristã reúne textos de origem oral e escrita elaborados ao longo de mais de mil anos.

A partir do segundo milênio a. C., dificilmente se registram mitos em que a divindade primária seja a mulher. Em sua maioria, são substituídas por um deus macho, como nos mitos persa, meda, e até o nosso mito cristão.

Javé é deus único, onipresente e onipotente. Cria sozinho o mundo em sete dias, e, no final cria o homem, para depois criar a mulher. Tudo é perfeito até que, graças à sedução da mulher, o homem cede à tentação da serpente e o casal é expulso do paraíso.

Ao contrário das culturas primitivas, Javé é deus único, centralizador, característica da cultura patriarcal. Nas primitivas mitologias, a Grande Mãe é permissiva, amorosa e coercitiva, características da cultura matricêntrica.

\footnotetext{
${ }^{2}$ HILÁRIO JÚNIOR, 1996. p. 53.

${ }^{3}$ HILÁRIO JÚNIOR, 1996. p. 58.

${ }^{4}$ HILÁRIO JÚNIOR, 1996. p. 59.
} 
O Jardim das Delícias é a lembrança arquetípica da harmonia entre o ser humano e a natureza, existente nas sociedades matricêntricas. Na sociedade patriarcal, em que prevalece a dominação do ser humano, essa antiga harmonia se rompe, e a separação é inevitável.

Com o trabalho penoso, é necessário um poder central que controle e puna a transgressão. A coerção e a violência são os meios encontrados para obrigar o homem a trabalhar, sendo essa coerção localizada no corpo, na repressão da sexualidade e do prazer. Daí o pecado original, a culpa máxima ser colocada no ato sexual, e, conseqüentemente na mulher, pois esta era o principal veículo da transgressão.

No Cristianismo Eva foi submetida ao parto com dor, numa retaliação ao ato sexual sujo e proibido. Ainda no Cristianismo, Maria permite a redenção de Eva, ao ser imaculada/assexuada, sendo a sexualidade o divisor de águas entre o feminino sacralizado e o profano. ${ }^{5}$

A árvore do conhecimento também se divide entre dois pólos (o bem e o mal). Enquanto fonte de conhecimento para o trabalho, é do bem, entretanto, quando esse conhecimento atinge a transgressão da lei do Pai, o prazer através do sexo, por exemplo, é proibido e, portanto, do mal. Essa divisão deu origem a todas as outras como sexo/ afeto, corpo/alma, e todas as fragmentações do homem e da mulher.

A tradição judaico-cristã caracteriza-se pela ordem patriarcal, que, como sabemos, estabelece uma relação de dominação. Assim como o homem é escravizado pelo trabalho, este escraviza a mulher. A relação homem-mulher-natureza não é mais de integração, e sim de dominação. O desejo dominante é o do homem, o desejo da mulher será para sempre insatisfeito.

A misoginia que caracteriza a cultura patriarcal só pode ser entendida quando se analisa a maneira pela qual as ciências psicológicas apontam as diferenças entre a estrutura psíquica feminina e masculina.

O menino reage mais violentamente à tragédia da castração imaginária do que a menina. Daí as diferenças que caracterizam a mulher e o homem serem tão evidentes. A mulher não enfrenta grandes conflitos com a mãe e sua identificação se resolve sem grandes traumas. Por isso não se divide de si mesma como se divide o homem, nem de suas emoções.

${ }_{5}^{5}$ ALMEIDA, 1994. p. 1. 
Para o resto da vida, conhecimento e prazer, emoção e inteligência são mais integrados na mulher do que no homem e, por isso, são perigosos e desestabilizadores para um sistema que reside no controle, no poder, num conhecimento completamente dissociado da emoção. ${ }^{6}$

A mulher representa uma ameaça à sociedade patriarcal e sua ordem vigente. Por isso é preciso precaver-se de todas as maneiras contra a mulher, impedi-la de interferir nos processos decisórios e, principalmente, fazer com que ela introjete uma ideologia que a convença de sua própria inferioridade em relação ao homem.

Encontramos na Bíblia o primeiro indício desta desigualdade entre homens e mulheres. Sabemos que a mulher foi criada (parida) de uma costela de Adão. Este é um mecanismo de defesa conhecido por todos aqueles que lidam com a psique humana, e serve para 'revelar escondendo'. Como o homem é capaz de parir (da costela), o que antes era sagrado e só pertencia à mulher agora é uma vulnerabilidade. Desde então, invertem-se os papéis, não é mais o homem que inveja a mulher. Ela passa a ser um reflexo do homem e só se vê através dele.

A tradição judaico-cristã exerceu um papel fundamental dentro da nossa cultura patriarcal e tem servido ininterruptamente para conservar a imagem feminina tradicional.

A mulher é vista como a tentadora do homem, é impura e culpabilizada pelo pecado de homens justos e de alma nobre. Ela é ligada à natureza, à carne, ao sexo e ao prazer. A serpente, que nas eras matricêntricas era o símbolo máximo da fertilidade e da sabedoria, se transforma no demônio, no tentador, na fonte de todo pecado.

O sexo é visto como o pecado supremo, fonte do desvairio do homem, desviando assim a crítica às estruturas do poder. Isso explica como os homens e as classes dominantes tiveram seu status sacralizado até hoje, já que à mulher e a sua sexualidade são atribuídas as causas máximas da degradação humana.

Eva é o protótipo da mulher moldada pelo Deus judaico-cristão, que sendo Pai e Todo-Poderoso, quis estabelecer um padrão eterno de conduta para a mulher: seja mulher de algum Adão, porque foi criada de sua costela (pedaço do homem e não criação independente de Deus). E que sua posição social esteja atrelada à responsabilidade pela preservação do casamento e pela felicidade do lar (marido e filhos).

${ }^{6}$ MURARO, [s.d.]. p. 11. 
Aqui está bem representada a divisão na tradição judaico-cristã onde se afirma a superioridade do homem sobre a mulher, através do mito de Eva e da redenção de Maria, explicitando no contexto histórico, político e religioso todos os interesses que alicerçam as bases da nossa cultura ocidental e, evidenciando a construção de um conceito feminino pautado em funções bipolares: sagrado enquanto maternal e profano enquanto sexual.

\section{Florbela Espanca e Gilka Machado: produtoras de uma poética corporal ou de uma erótica verbal}

Florbela Espanca é um caso singular na literatura portuguesa, tanto quanto Gilka Machado o é na literatura brasileira.

As semelhanças entre as obras poéticas de Florbela Espanca e Gilka Machado se estendem também em relação à recepção por parte da crítica em suas respectivas épocas. Ambas não tiveram um lugar de destaque na crítica tradicional, tendo, como conseqüência, a exclusão do cânone literário.

A questão que aproxima tanto estas poetisas é a da fala diferente que se traduz numa linguagem tipicamente feminina (do sujeito feminino), suscitando uma intrínseca relação entre erotismo e poesia. Tal relação é definida por Octavio $\mathrm{Paz}^{7}$ como, no primeiro caso, uma poética corporal e, em seguida, como uma erótica verbal.

Para Paz, a relação que a poesia tem com a linguagem é semelhante à do erotismo com a sexualidade, pois ambos são feitos de uma oposição complementar. Entre a poesia e a linguagem existe um desvio de seu fim natural: a comunicação, pois a linearidade, pressuposto básico da linguagem, se torce no poema. Entre o erotismo e a sexualidade também ocorre um desvio, pois na sexualidade o prazer serve para a procriação e, no erotismo, o prazer é um fim em si mesmo. Assim, ambas as relações se correspondem e se opõem, complementarmente.

A linguagem utilizada pelas poetisas é predominantemente erótica e sensual, sem precedentes na poesia portuguesa e na poesia brasileira. Essa é a grande inovação da vertente temática que ambas autoras

${ }^{7}$ PAZ, 1994. p. 12. 
introduzem em suas obras: a descrição detalhada do desejo e do prazer femininos como sujeito, e não como objeto, o que feria diretamente os preceitos básicos da sociedade burguesa-cristã.

Nos poemas a seguir explicita-se essa tendência:

\section{Tuas mãos são quentes}

Tuas mãos quentes, muito quentes

(mas que arrepios, minha carne, sentes, aos seus macios dedos!...); Tuas mãos são muito quentes, mas teus afagos me parecem frios como os esguios corpos das serpentes. (...)

Por essas mãos é que me dizes Todas as coisas Que não ousas dizer com a fala, as confidências que teu lábio cala aos meus ouvidos infelizes (...) tuas mãos acordam ruídos na minha carne, nota a nota, frase a frase; colada a ti, dentro em seu sangue quase, sinto a expressão desses indefinidos silêncios da alma tua, a poesia que tens nos lábios presa, teu inédito poema de tristeza, vibrar, cantar, na minha pele nua.

(Gilka Machado, O grande amor, 1928)

\section{Volúpia}

(...)

A sombra entre a mentira e a verdade...

A nuvem que arrastou o vento norte...

- Meu corpo! Trago nele um vinho forte:

- Meus beijos de volúpia e de maldade!

(...)

E do meu corpo os leves arabescos

Vão-te envolvendo em círculos dantescos

Felinamente, em voluptuosas danças..

(Florbela Espanca, Charneca em flor, 1931, póstuma) 
$\mathrm{Na}$ fala assumidamente erotizada, a característica inovadora que salta aos olhos, na obra das poetisas, é a subversão dentro da tradição/criação literária feminina, já que tal característica explicita um comportamento contrário àquele introjetado pela cultura e, conseqüentemente, pela literatura, atribuído ao sujeito feminino.

Segundo Magalhães, ${ }^{8}$ na poesia ocidental, a sexualidade feminina foi usada constantemente pelas vozes masculinas para escarnecer das mulheres: como vituperatio. Florbela e Gilka, todavia, extraem a mulher vituperada da tradição, invertendo e subvertendo a situação, transformandoa em auto-laudatio.

Mas essa é apenas uma face do todo que constitui o rico e complexo processo de criação das poetisas. Tal característica aponta, ainda, para uma direção mais inovadora e mais subversiva; trata-se de um despojamento do eu feminino, no qual ressaltam a própria individualidade e o desapego frente a relacionamentos e amores desfeitos. Essa característica, já observada por Massaud Moisés, José Régio e Augustina Bessa Luís, na obra de Florbela Espanca, é classificada como o donjuanismo. Encontramos fortes semelhanças com a obra de Gilka Machado também neste aspecto. Vejamos os poemas:

\section{Inconstância}

(..)

Passei a vida a amar e a esquecer...

Atrás do sol dum dia outro a aquecer

As brumas dos atalhos por onde ando...

E este amor que assim me vai fugindo

É igual a outro amor que vai surgindo,

Que há de partir também... nem eu sei quando...

(Florbela Espanca, Livro de Sóror Saudade, 1923)

\section{Embora de teus lábios afastada}

Embora de teus lábios afastada

(Que importa? - Tua boca está vazia...)

Beijo esses beijos com que fui beijada

Beijo teus beijos numa nova orgia.

${ }^{8}$ MAGALHÃES, 1994. p. 219. 


\section{(...)}

Teus beijos absorvi-os, esgotei-os: guardo-os nas mãos, nos lábios e nos seios, numa volúpia imorredoura e louca.

Em teus momentos de lubricidade, beijarás outros lábios, com saudade dos beijos que roubei de tua boca.

(Gilka Machado, Meu glorioso pecado, 1928)

O que se vê é que tanto Florbela quanto Gilka contrariam os paradigmas da relação homem-mulher, já que a inconstância no amor sempre foi atributo oferecido aos homens. Sant'anna ${ }^{9}$ explica tal tendência como uma "variante do dândi sedutor" que funciona como o prostituto que mistura amor e morte no mesmo leito de enganos. Na poética florbeliana e gilkiana, essa característica se explicita, mesmo que inconscientemente, quando observamos o duplo movimento no qual ambas circulam entre o amor e o erotismo, já que a tendência donjuanesca não é uma constante. Contudo, note-se que o donjuanismo se reitera, quando pensamos que amor e morte são duas faces de uma mesma moeda, na figura de Don Juan.

A face donjuanesca de Florbela e Gilka Machado se dá, principalmente, nos poemas citados, pela inexistência da entrega amorosa. A mulher prevalece sobre a alma do amante simulando o desejo, mas sendo o seu próprio sujeito feminino o objeto desejado. Atente primeiramente para o trecho de Florbela:

(...) E este amor que assim me vai fugindo

É igual a outro amor que vai surgindo,

Que há de partir também... nem eu sei quando...

Na mesma linha, o poema de Gilka:

(...) Embora de teus lábios afastada

(Que importa? - Tua boca está vazia...)

Beijo esses beijos com que fui beijada

Beijo teus beijos numa nova orgia. (...)

\footnotetext{
${ }^{9}$ SANT'ANNA, 1984. p. 223.
} 
De acordo com BRUNEL, ${ }^{10}$ o mito de Don Juan define-se basicamente pela mudança e inconstância, e é essa a característica que mais se assemelha às tendências das poetisas, como se pode observar.

PAZ, ${ }^{11}$ definindo amor e erotismo aproxima Don Juan da concepção platônica do amor. Para o autor, Don Juan é subversivo, pois é a imagem invertida do eros platônico. Nessa relação explicita-se, ainda, um dos traços mais marcantes que definem o eixo condutor das obras dessas poetisas frente à tradição judaico-cristã: a virtude e a beatitude, atributos do sagrado, opõem-se diretamente ao prazer físico, atributo do profano, revelando, mais uma vez, relações que se opõem e se complementam.

A complexidade dessa tendência é muito profunda e rica, deixando entrever a essência do ato criador dessas poetisas, o que pode ser melhor compreendido à luz da análise de Jung, no que ele define como relação entre a consciência e o inconsciente por um lado e, processo de individuação por outro. Os processos inconscientes pertencem à totalidade do indivíduo, mesmo que não sejam componentes do eu consciente ou tenham pouquíssima relação com ele, manifestando-se na conduta humana.

O inconsciente é capaz até mesmo de assumir o papel do eu, em certas circunstâncias, acarretando insanidade e confusão, já que o mesmo representa uma soma descentralizada de processos psíquicos. Nossa consciência desenvolveu-se tanto histórica como individualmente a partir da escuridão ou estado crepuscular da inconsciência originária. "O 'pensar' existia antes do homem dizer 'eu tenho consciência do que penso'."12

Partindo do pressuposto que o sexo é determinado por uma maioria de genes masculinos e femininos e a minoria dos genes do outro sexo não desaparece, Jung desenvolveu um conceito para definir essa forma feminina inconsciente, chamando-a anima. Para a forma masculina inconsciente Jung nomeou animus. "No inconsciente de cada homem está oculta uma personalidade feminina e há uma personalidade masculina em cada mulher." ${ }^{13}$

\footnotetext{
${ }^{10}$ BRUNEL, 1998. p. 256.

${ }^{11}$ PAZ, 1994. p. 46.

${ }^{12}$ JUNG, 2000. p. 274.

${ }^{13}$ JUNG, 2000. p. 277.
} 
O processo de individuação consiste no desenvolvimento produzido pelo conflito de duas realidades anímicas fundamentais.

Segundo Jung, ${ }^{14}$ "individuação" significa tornar-se um ser único, na medida em que por "individualidade" entendemos nossa singularidade mais íntima, última e incomparável, significando também que "nos tornamos o nosso próprio si mesmo". É por este motivo que a individuação é um mistério da unificação, dado que o si-mesmo é percebido como a união das polaridades, portanto, como uma totalidade, na qual o indivíduo acolhe em si mesmo o bem e o mal em todos os aspectos.

Nesse sentido, a tendência donjuanesca explicita uma inconsciência poética das poetisas que foge ao senso comum, extrapolando a consciência comum do ser humano. Mas qual seria a essência dessa inconsciência que levou essas duas poetisas a trilharem um caminho tão diverso dos estabelecidos pelo cânone literário da época?

Para Jung, ${ }^{15}$ todas as épocas têm suas especificidades e podem ser comparadas à alma de um indivíduo; apresenta uma situação consciente específica e restrita, necessitando, portanto, de algo que supra as necessidades, mas que não pode ser encontrado ou percebido pelo senso comum. E é através da arte ou de tudo aquilo que pode exprimir o inexprimível que se chega à compensação e à salvação de uma situação.

Ambas utilizam a arte para exprimir a insatisfação e reivindicar uma posição na qual o sujeito feminino expressa as suas verdadeiras necessidades e vontades, encontrando na fala do desejo a via dessa expressão, pois "se a literatura reflete a civilização em seus aspectos formais, sociais e psíquicos, não há como o sujeito, o poeta, exprimir seus sentimentos desvinculados de seu imaginário, seja ele masculino ou feminino." ${ }^{16}$

Noutros poemas das poetisas ainda subsiste a tendência donjuanesca:

\section{Adeus}

Adeus. Não me ouvirás lamúrias loucas;

saberei saborear esta tortura,

que, se as horas de amor nos foram poucas, é na saudade que a afeição se apura.

\footnotetext{
${ }^{14}$ JUNG, 1979. p. 49.

15 JUNG, 1991. p. 87.

${ }^{16}$ SILVA, 1999. p. 25.
} 
Hão-de te parecer de espírito ocas as expressões de outra qualquer criatura, e em vão procurarás nas outras bocas paladar para tua formosura.

(...) E sofrerás dentre os silêncios lentos, ânsia do teu louvor na minha frase, fome da carne dos meus pensamentos.

(Gilka Machado, Meu glorioso pecado, 1928)

\section{Supremo enleio}

Quanta mulher no teu passado, quanta! Tanta sombra em redor! Mas que importa? (...)

Quando eu for uma pobre coisa morta, Quanta mulher ainda! Quanta! Quanta! Mas eu sou a manhã: apago estrelas! Hás de ver-me, beijar-me em todas elas, Mesmo na boca da que for mais linda!

E quando a derradeira, enfim, vier, Nesse corpo vibrante de mulher Será o meu que hás de encontrar ainda...

(Florbela Espanca, Charneca em flor, 1931, póstuma)

Observa-se nestes poemas um tom que ultrapassa a tendência do donjuanismo e estabelece um jogo de poder, no qual o sujeito feminino, mais uma vez, subverte a relação tradicional, colocando-se como um alguém que apesar de não estar mais na relação, representa e significa muito mais, sendo, portanto, uma presença eterna na vida do amante.

Observe-se os seguintes trechos, primeiramente de Gilka:

(...) E sofrerás dentre os silêncios lentos, ânsia do teu louvor na minha frase, fome da carne dos meus pensamentos.

E os de Florbela:

(...) Quanta mulher no teu passado, quanta!

Tanta sombra em redor! Mas que importa? 
Ambas as poetisas deixam entrever em seus poemas a presença marcante não só no presente, mas também no futuro, como se delas (o sujeito feminino) o amante não mais pudesse se apartar. É nesse crescente que a poesia dessas autoras refletem o imaginário do sujeito feminino tão particular e subversivo dentro da literatura de seus países, reivindicando uma cultura diferente, feminina.

\section{Considerações Finais}

As marcas da trajetória poética de Florbela Espanca e Gilka Machado são consideradas como um marco na literatura portuguesa e brasileira, não só pela qualidade de suas obras mas, sobretudo, pela ousadia e, principalmente, pelas diversas faces que apresentam. A ousadia se reflete no princípio fundador de uma cultura que exercitou-se na lógica do masculino para melhor se fazer entender no espaço público, encontrando resistências e incompreensões.

Vão do erótico ao religioso, da sublimação ao êxtase, e em meio às diversas faces que apresentaram, conseguiram captar a essência de uma situação que apesar de insatisfatória, embora esmagadora, estava estruturada sobre bases sólidas.

Se hoje a voz feminina evoluiu da modesta ambição de se fazer ouvir no espaço público, para instaurar uma nova Razão, a Razão do Feminino, podemos concluir que essa ousadia consistiu num passo fundamental na luta pela igualdade de direitos da mulher.

A face erotizada que se converte na face donjuanesca é apenas mais uma das muitas outras que se inserem no complexo processo de criação dessas poetisas.

Contudo, a face que se impõe como essencial é aquela da eterna busca da identidade feminina e, talvez por isso, o processo de criação seja múltiplo, multifacetado. A revolução do corpo foi e continua sendo um fato decisivo na história do amor e do erotismo

A tomada de consciência se dá pela gradativa descoberta de uma nova relação com o corpo e com o prazer e configura-se como o início da trajetória responsável pela construção da identidade feminina.

O processo de individuação se mostra evidente nos embates entrevistos nas obras das poetisas. O combate entre o consciente e o 
inconsciente que ambas propõem em suas obras se revela honesto e com o mesmo direito de ambos os lados. Isto significa que as poetisas buscaram seguir os seus caminhos, defendendo a razão por parte da consciência, ao mesmo tempo em que davam vazão ao aspecto caótico e irracional do inconsciente, retratado na liberação das idéias e emoções que anteciparam os ideais de formação da cultura feminina.

O projeto que inaugura o ideal libertário, quanto ao tema das sensações do prazer sexual, na literatura, foi alicerçado, no Brasil, por Gilka Machado e por Florbela Espanca em Portugal, sendo essa uma das maiores conquistas dessas mulheres, rebeldes, corajosas e escritoras.

\section{Referências Bibliográficas}

ALMEIDA, Maria Emília de Souza. Algumas considerações a respeito do feminino na Teoria Freudiana. Trabalho apresentado ao Instituto de Psicologia da USP, 1994.

BRUNEL, Pierre. Dicionário de mitos literários. Trad. Carlos Sussekind. 2. ed., Rio de Janeiro: José Olympio, 1998.

ESPANCA, Florbela. Poemas de Florbela Espanca. Estudo introdutório, organização e notas de Maria Lúcia Dal Farra. São Paulo: Martins Fontes, 1996.

HILÁRIO JÚNIOR, Franco. Cristianismo medieval e mitologia. In: A eva barbada. São Paulo: Edusp, 1996.

JUNG, Carl Gustav. Os arquétipos e o inconsciente coletivo. Trad. Maria Luíza Appy, Dora Mariana R. Ferreira da Silva. Petrópolis: Vozes, 2000.

. O eu e o inconsciente. Trad. Dora Mariana R. Ferreira da Silva. Petrópolis: Vozes, 1979.

. O espírito na arte e na ciência. Trad. Maria de Moraes Barros, 3. ed., Petrópolis: Vozes, 1991.

MACHADO, Gilka. Poesias Completas. Nova edição. Rio de Janeiro: Léo Christiano Editorial:/FUNARJ, 1991.

MAGALHÃES, Isabel Allegro. Florbela Espanca e a subversão de alguns Topoi. In: A planície e o abismo (Actas do Congresso sobre Florbela espanca, realizado na Universidade de Évora, de 7 a 9 de dezembro de 1994). 
MURARO, Rose Marie. Breve Introdução Histórica. In: O martelo da feiticeiras. Trad. Paulo Fróes, 7. ed. [s.d.].

PAZ, Octavio. A dupla chama / amor e erotismo. Trad. Wladir Dupont. São Paulo: Siciliano, 1994.

SANT'ANNA, Afonso Romano de. O canibalismo amoroso; o desejo e a interdição em nossa cultura através da poesia. São Paulo: Brasiliense, 1984.

SILVA, Cleonice Nascimento da. A releitura do conceito: imagem feminino na poética de Ida Laura e Lenilde Freitas. Dissertação (Mestrado UNESP/ Assis), 1999 .

\section{Resumo}

Este trabalho tem como objetivo apresentar como está representada a imagem feminina em alguns poemas selecionados da obra de Florbela Espanca e Gilka Machado.

As marcas de sensualidade e o natural rompimento com a tradicional visão do amor no discurso feminino, atuam como características predominantes do universo poético dessas poetisas.

Tais características explicitam o processo de individuação feminina que reflete em seu discurso libertário e irreverente uma espécie de donjuanismo feminino. Nosso propósito é focalizar a construção desse processo de individuação feminina que, se por vezes mostra uma sensibilidade exacerbada por fortes impulsos eróticos, por outras, revela toda a angustiante experiência sentimental nas quais as poetisas extravasam as lutas que travam dentro de si entre tendências e sentimentos opostos.

Acreditando que a trajetória e a representação da imagem feminina no discurso poético florbeliano e gilkiano refletem uma proposta pioneira de valores transgressores da sociedade burguesa cristã, o estudo mostra o perfil da mulher na obra de Florbela Espanca e de Gilka Machado. 


\section{Resume}

This written work aims to show how Florbela Espanca and Gilka Machado have represented the feminine image in some selected pieces of their poetry oeuvre. Sensuality traits and natural rupture with the traditional point of view about love affection within feminine discourse act as predominant features into the authors' poetic universe.

Such features expound the women individualization process which express through authors' setting-free and non-obeying discourse a kind of feminine donjuanism.

It is intend here to spot the building of this feminine individualization process. sometimes this building process exposes a sensibility exaggerated by strong erotic impulses, and in others times that process reveals the very sentimental anghuishening experience through which both poets set free their inner struggles involving oppostie tendencies and feelings.

This study draws a woman's profile inside Floberla Espanca and Gilka Machado's poetry by taking for granted that the feminine image trajectory and representation within authors' poetic discourse expresses a pioneer proposal of breaking-rules values of christian burgeois society. 